Article

\title{
A Novel Optimization Algorithm to Create Perennial Calendar System based on Gregorian and International Fixed Calendards
}

\author{
Claude Ziad El-Bayeh
}

\begin{abstract}
Has anyone ever missed an event because he was confused in days and dates? Do we remember the date of any day without looking at a calendar? Is the current Gregorian Calendar efficient enough for use, and does it facilitate our life or make it more complicated? Have you ever thought about a much simpler way to calculate days and dates in a year? All these questions are answered in this paper, in which the author proposes original optimization algorithm that creates optimal perennial calendars. Results show that there is more than one way to create a perennial calendar, in which the number of days in each month does not change, neither the dates. Hence, all months have the same sequence of days and dates. In other meaning, Monday becomes the first day of every month, and Sunday becomes the last day. Consequently, the calendars become much easier to memorize and very simple to predict the days and dates in any year.
\end{abstract}

Keywords: Gregorian Calendar; Weekly-based Calendar; Original Calendar; Optimization algorithm; Energy saving.

\section{Introduction}

\subsection{Background and Motivation}

From the early beginning of human civilizations, people realized the importance of organizing their daily [1]. Many cultures created their calendars and dating systems that helped them to save religious and social activities and events [1]. The most recognized calendars in the ancient time include but not limited to, Roman calendar [2], [3], Sumerian calendars [4], [5], Babylonian calendar [6], Zoroastrian calendar [7], Hebrew calendar [8], Hellenic calendars [9] and Julian calendar [10]. In the late of the sixteenth century, the Gregorian calendar (GC) was introduced by Pope Gregory XIII on October 15, and was later adopted worldwide [11]. In the Gregorian calendar, a year is composed of 12 months. Each month has a different number of days. For example, January has 31 days, February has 28 days, and 29 in a leap year, April has 30 days, and so on. One of the main critics of the Gregorian calendar is that it is very difficult to find a simple relationship between dates and days [12]. Sometimes, the dates become confusing especially when a particular day like Monday, is the first day in a month, and the second or even the seventh in another month, sometimes holidays which are on a specific date such as December 24, could be located during the weekdays (e.g., in 2019), while it can be in weekends in another year (e.g., 2022). Hence, calculating days and dates is a difficult task, because of the irregularities in the Gregorian calendar. It appears that the existing calendar system becomes a little bit confusing for most of the people, and a much simpler calendar is needed. In addition, billions of calendars are printed every year worldwide, in which millions of trees are used 
every year to supply the demand. The emission of $\mathrm{CO} 2$, the pollution, the waste, and the energy used to print out Gregorian calendar cannot be neglected especially when around billions of calendars are thrown every year. Therefore, Gregorian calendar imposes negative impact on the society, the economy, and the environment, in which a solution should be proposed to facilitate the life of people and create a more sustainable and greener society.

Some questions may arise. What happens if we create a more organized calendar in which the days and dates in a month do not change? For example, Monday will always be the first day of any month. The holidays will have the same dates and days in any year. For example, December 24, will always be on Wednesday, whatever is the year. Can we create an eco-friendly calendar, which is very easy to memorize without the necessity to print a hard copy to reduce the pollution? Moreover, human beings always tend to develop and invent new things every day to facilitate their lives. So why do we not develop an easier way to count days, weeks, and months in a year?

\subsection{Gregorian vs. Julian Calendars}

A year is the time a given celestial object (e.g., Earth, Mars, etc.) takes to complete one orbit around another celestial object (e.g., Sun), also called orbital period. However, astronomical years do not have integer numbers of days; for example, the Earth orbits the Sun in about 365.2425 days; therefore, it is necessary to introduce the intercalation system such as leap years. Julian and Gregorian calendars are the most common ones these days. A Julian calendar counts 365.25 days in a year, while 365.2425 days are considered in the Gregorian calendar. In total, a leap year occurs every four years in the Julian calendar, in which one day is added to the month of February. The Gregorian calendar follows almost the same concept; however, some new rules were added to reduce the gap with the reference (365.2422 days per year). These new rules are cited as follows:

Every year that is exactly divisible by four is a leap year, except for years that are exactly divisible by 100, but these centurial years are leap years if they are exactly divisible by 400. For example, the years 1700, 1800, and 1900 are not leap years, but the years 1600 and 2000 are [13].

These new rules reduce the error by 1.2 days every 4,000 years, as shown in the following table, while the Julian calendar shows an error of 31.2 days. From this place, the Gregorian calendar was adopted until this time.

\begin{tabular}{|l|c|c|c|c|c|c|}
\hline Calendar & $\begin{array}{c}\text { Number } \\
\text { of days in } \\
\text { a year }\end{array}$ & $\begin{array}{c}\text { Number of } \\
\text { days in 4 } \\
\text { years }\end{array}$ & $\begin{array}{c}\text { Number of } \\
\text { days in 400 } \\
\text { years }\end{array}$ & $\begin{array}{c}\text { Number of } \\
\text { days in } \\
\mathbf{4 , 0 0 0 ~ y e a r s ~}\end{array}$ & $\begin{array}{c}\text { Error per 400 } \\
\text { years with respect } \\
\text { to the reference }\end{array}$ & $\begin{array}{c}\text { Error per 4,000 } \\
\text { years with respect } \\
\text { to the reference }\end{array}$ \\
\hline Julian & 365.25 & 1,461 & 146,100 & $1,461,000$ & 3.12 & 31.2 \\
\hline Gregorian & 365.2425 & $1,460.97$ & 146,097 & $1,460,970$ & 0.12 & 1.2 \\
\hline Reference & $\mathbf{3 6 5 . 2 4 2 2}$ & $\mathbf{1 4 6 0 . 9 6 8 8}$ & $\mathbf{1 4 6 0 9 6 . 8 8}$ & $\mathbf{1 , 4 6 0 , 9 6 8 . 8}$ & - & - \\
\hline
\end{tabular}

\subsection{International Fixed Calendar}

The Gregorian calendar has serious problems and flaws. The main problem of the Gregorian calendar is that the number of days in months is not fixed, and it may vary between 28 and 31 days per month. Moreover, a month can start on Monday (June 1,2020) and the next one on Wednesday (July 1, 2020). Therefore, there is no consistency between days and dates. The date of February 29 
occurs every four years, which seems unpleasant to some people. Moreover, a year is divided into four quarters ( 3 months each quarter). If the number of days is counted in each quarter, it appears that the first quarter has 90 days, the second one has 91 days, and the third and fourth one has 92 days. The quarters are not symmetrically distributed. Therefore, two additional working days in a quarter can make a difference in the statistics for a big company. In addition, holidays are not stable during the year, for example, Christmas on December 24 is on Thursday in 2020, while it is on Saturday in 2022. In conclusion, the Gregorian calendar is difficult to handle and to memorize. To solve the problem, other sophisticated calendars were proposed to facilitate our lives []. The most famous calendar is called International Fixed Calendar and also called Cotsworth calendar, which was introduced by Moses B. Cotsworth in 1902 [14]. The calendar divides the solar year into 13 months of 28 days each. This kind of calendars is defined as a perennial calendar, in which every weekday has a fixed date every year. The International Fixed Calendar has some rules to follow, as described below [14]:

- One year has 13 months

- Each month has exactly 4 weeks

- Each week has 7 days. Therefore, the total number of days in a year becomes equal to 364 (7 days $x 4$ weeks $x 13$ months)

- An extra day is added as a holiday at the end of the year, and it is called Year Day

- The Year Day does not belong to any week. Therefore, the total number of days, including the Year day in a year, becomes equal to 365 days.

- The Cotsworth calendar is correlated to the Gregorian calendar in which it has the same number of days, and each year starts on the same date, which is January 1.

- Costworth calendar has the same month's names and order as the Gregorian calendar, except the same as those of the Gregorian calendar, except that the extra month (called Sol), which is inserted between June and July [15].

- A leap year has 366 days, and its occurrence follows the Gregorian rules.

- The Leap-Day is inserted on June 29 (between Saturday, June 28, and Sunday, Sol 1).

- Each month starts on a Sunday and ends on a Saturday.

- Both Year-Day and Leap-Day do not belong to any week. They are preceded and followed by a Saturday and a Sunday, respectively.

Table 1 presents the International Fixed Calendar, in which the Leap-Day and the Year-Day are added to the end of months June and December.

Despite the success of this calendar, it received many critics, and it has some drawbacks. The most common critics can be presented as follows:

a. The calendar claimed to have exactly 28 days in each month. However, when the leap day is added, June month will contain 29 days and not 28 . The same for the leap-year, in which it is added to the month of December. Hence, the total number of days becomes equal to 29 .

b. The calendar has 13 months, which is a prime number and cannot be divided by 2 , nor by 3 neither by 4 . Therefore, it becomes difficult to categorize activities based on a biannually, triannually, or quarterly basis. Thus, activities will be out of alignment with months.

c. The week starts with a Sunday. Hence, the calendar disagrees with ISO 8601, in which the first day is Monday and not Sunday.

d. Adding a day between Saturday and Sunday is considered confusing, especially when leap-day and year-day are added to the month of June and December.

e. Some people are pessimistic about the date Friday $13^{\text {th }}$.

f. Actually, the weekday starts on the second of each month and not on the first. 
Table 1: International Fixed Calendar.

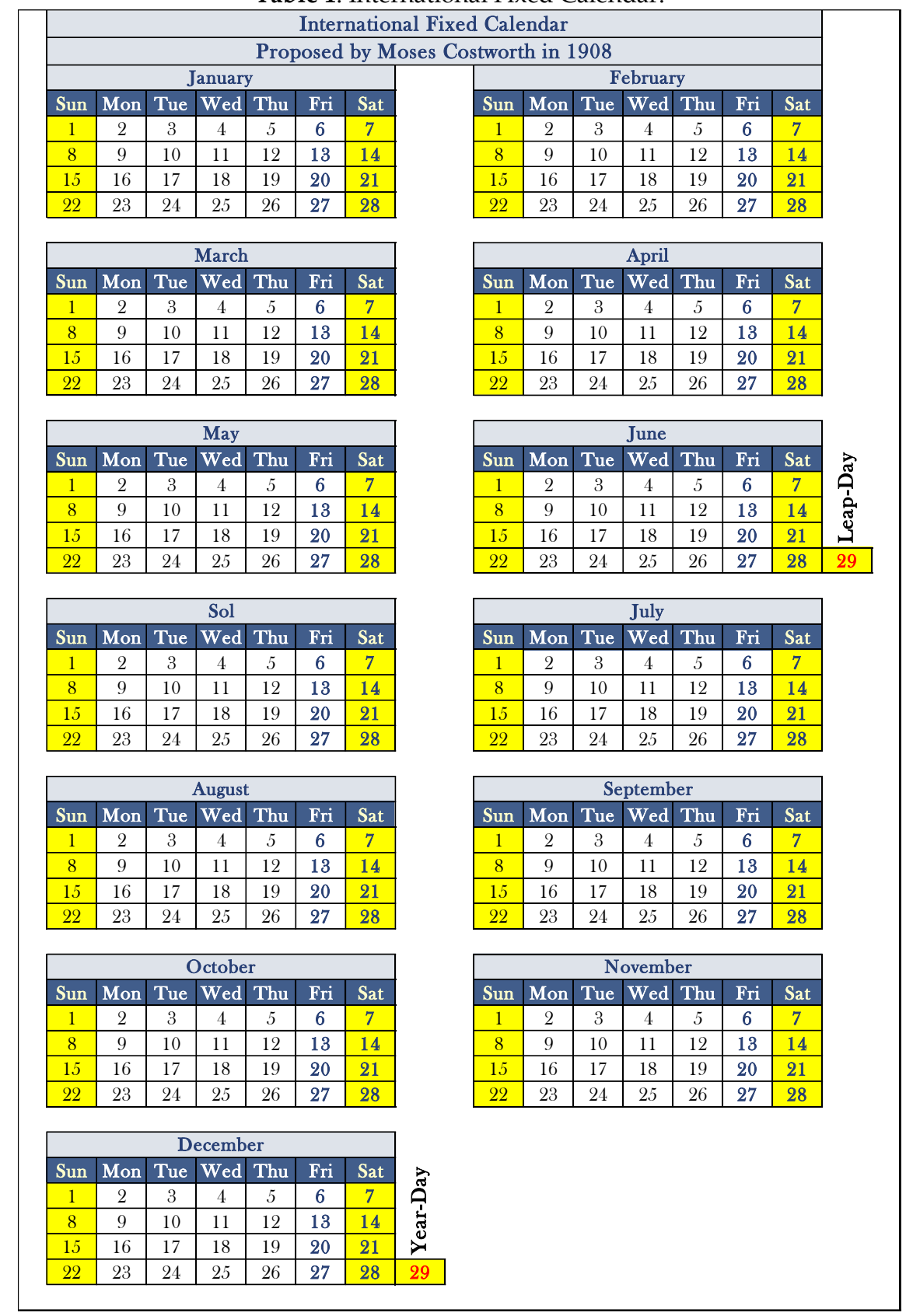

\subsection{Contributions}

In this paper, the main contributions are presented as follows:

- An original perennial calendar system is proposed that solves all the above-mentioned problems.

- A 14 months calendar instead of 13 is considered, in which the last one is called Month zero. Month zero has only one day in a year with 365 days and two days in a leap year.

- An original optimization algorithm that generates perennial calendars is proposed. An objective function and some constraints are defined for this purpose. The algorithm is solved with Mixed Integer Genetic Algorithm.

To validate our concept, the proposed calendar is compared to the Gregorian calendar and the International Fixed calendar. The advantages and disadvantages are discussed briefly. 


\section{Proposed Perennial Calendar}

The idea of creating a perennial calendar such as the International Fixed Calendar (IFC), is promising, and it can solve lots of problems. However, the IFC has many drawbacks, as mentioned previously. To reduce these drawbacks, new perennial calendars are proposed based on the idea of the IFC, the Gregorian calendar, and using the optimization model. To do so, a new annotation will be used in this paper to refer to a specific calendar. The annotation is as follows:

\section{MWD+R}

Or simply the mathematical Equation can be written as

$$
\mathrm{M} \times \mathrm{W} \times \mathrm{D}+\mathrm{R}=366 \text { days in a leap year }
$$

In which, $\mathrm{M}$ presents the number of months in a year (e.g., $\mathrm{M}=12$ months in a year). W shows the number of weeks in a day (e.g., $\mathrm{W}=4$ weeks in a month). $\mathrm{D}$ stands for the number of days in a week (e.g., $\mathrm{D}=7$ days in a week). $\mathrm{R}$ describes the number of remaining days that fill the gap between a perennial calendar and the real number of days in a year. For example, calculate $\mathrm{R}$ if there are 12 months a year, 4 weeks a month, and 7 days a week. In this case, $M=12, W=4, D=7$. Hence,

$$
\begin{aligned}
\mathrm{M} \times \mathrm{W} \times \mathrm{D}+\mathrm{R} & =12 \text { months/year } \times 4 \text { weeks/month } \times 7 \text { days/week }+\mathrm{R}=366 \\
\mathrm{R} & =366-12 \times 4 \times 7=30 \text { remaining days per year }
\end{aligned}
$$

Based on the above-mentioned example, the number of remaining days per year is almost equal to one month for the Gregorian calendar. Therefore, the Gregorian calendar cannot be considered as a good example of a perennial calendar. From this place, the real number of months in a year should be equal to 13 in the above case. An ideal perennial calendar is when the remaining number of days in a year will be equal to zero, hence $R=0$. However, this is not possible for the Earth because the number of days in a year does not have an integer value, and it is equal almost to 365.2422. Therefore, it is necessary to rearrange the number days, weeks, and months in order to minimize R. Thus, it becomes an optimization problem in which we need to recalculate the number of months, weeks, and days in a way to minimize $R$.

\subsection{Optimization Model}

As discussed previously, to minimize the number of remaining days in a year, an optimization model should be created. The objective function is described in $\mathrm{Eq}(2)$, and the constraints are shown in Equations (3) to (7). Where, $R_{\min }$ and $R_{\max }$ describe the lower and upper bound of the number of remaining days in a perennial calendar. $M_{\min }$ and $M_{\max }$ are the lower and upper bound of the number of months per year. $W_{\min }$ and $W_{\max }$ represent the lower and upper bound of the number of weeks per month. $D_{\min }$ and $D_{\max }$ show the lower and upper bound of the number of days per week. It is obvious that the optimization problem is mixed-integer nonlinear programming in which M, W, D, and R should be integers. To solve the problem, the Mixed-Integer Genetic Algorithm (MIGA) is used in this paper.

Objective function:

$$
\text { Minimize } R=Y-M \cdot W \cdot D
$$


Claude Ziad El-Bayeh

Subject to:

$$
\begin{gathered}
R_{\min } \leq Y-M \cdot W \cdot D \leq R_{\max } \\
M_{\min } \leq M \leq M_{\max } \\
W_{\min } \leq W \leq W_{\max } \\
D_{\min } \leq D \leq D_{\max } \\
{[R, M, W, D] \in \mathbb{N}}
\end{gathered}
$$

\subsection{Optimization Algorithm}

To solve the above problem, Algorithm 1 is proposed and written in MATLAB 2018b. The initial values (such as Mmin, Mmax, etc.) can be changed according to the needs of the user.

\section{Algorithm 1: Optimization Model of the Proposed Original Perennial Calendar}

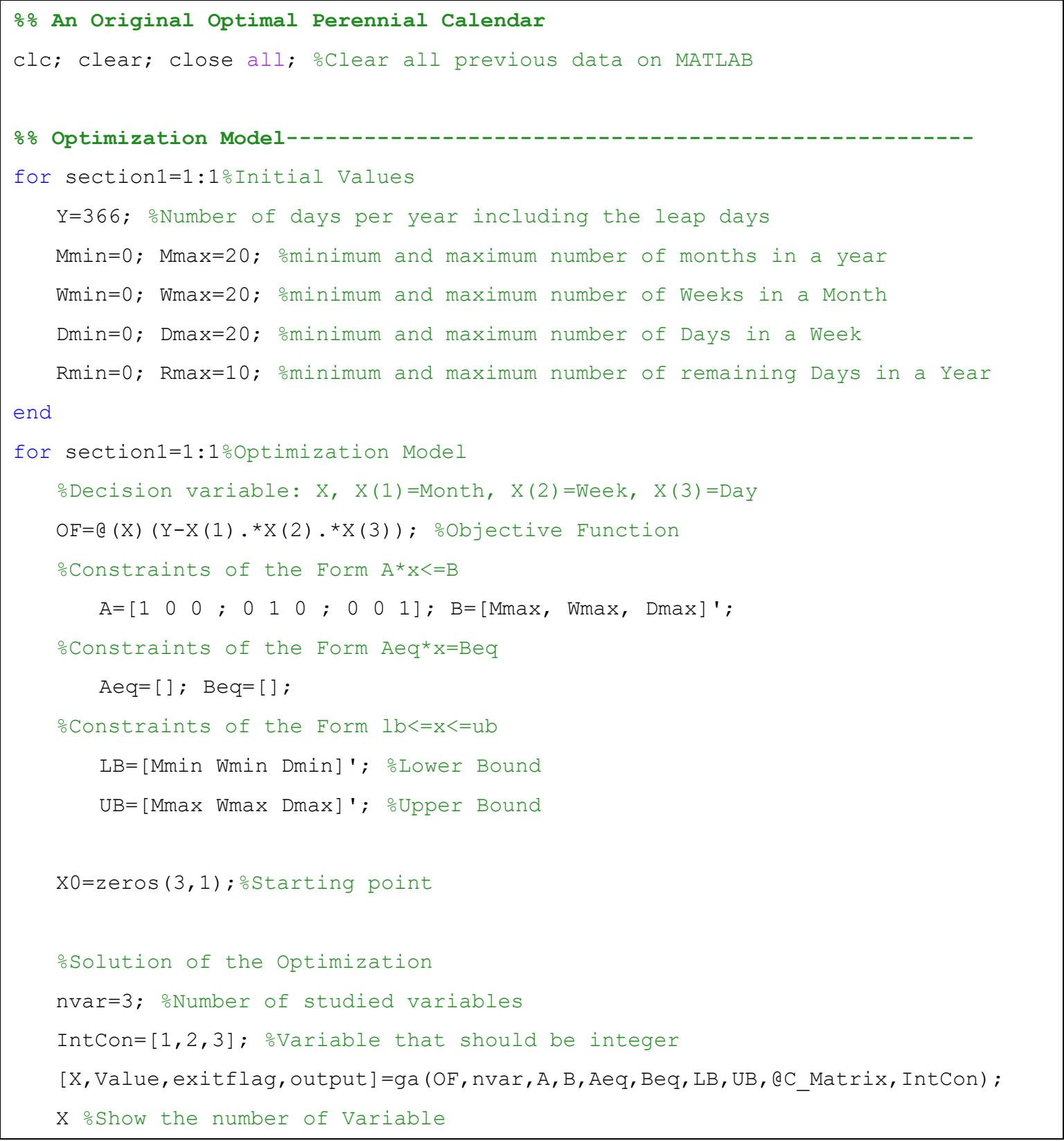




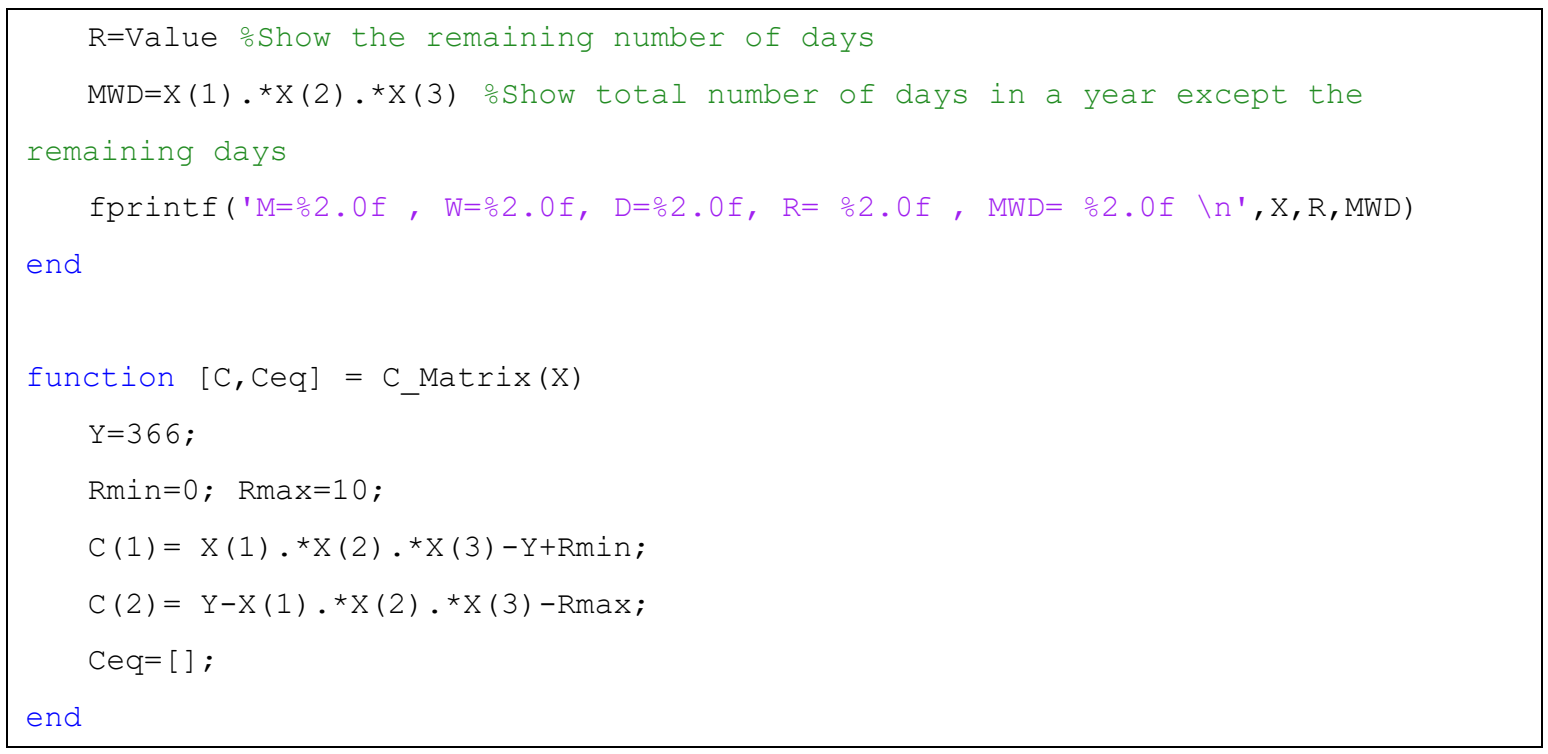

\section{Results and Discussions}

\subsection{Assumptions}

After defining the optimization model and algorithm, it is necessary to present the assumptions that are considered in this paper. The optimization model requires the user to set the boundaries of the constraints. For this purpose, the limits are defined as follows:

- The remaining number of days in a year: $\mathrm{Rmin}=0$ and $\mathrm{Rmax}=10$. By increasing the range, more options appear to the user to choose the best calendar that fits his needs.

- The number of months in a year: Mmin=10 and Mmax=20. We do not want a number of months less than 10 because they become very long.

- Number of Weeks in a month: Wmin=0 and Wmax=20. We set the number of weeks flexible in order to get more options.

- Number of Days in a week: Dmin=5 and Dmax=8. A number less than 5 represents a tooshort week, and a number greater than 8 is considered too long for a week.

\subsection{Output Results of the Algorithm}

Table 2 presents the output results for the number of months, weeks, days, and remaining days per year for the proposed perennial calendars. The values can change when the boundaries of the constraints change.

Table 2: Output Results of the Optimization Model

\begin{tabular}{ccccccccccccccc}
\hline \multicolumn{10}{c}{ Input } \\
\hline Options & Rmin & Rmax & \multicolumn{1}{c}{ Mmin Mmax } & \multicolumn{7}{c}{ Output } \\
\hline 1 & 0 & 10 & 10 & 20 & 0 & 20 & 5 & 8 & $\mathbf{1 0}$ & $\mathbf{6}$ & $\mathbf{6}$ & $\mathbf{6}$ & $\mathbf{3 6 0}$ \\
2 & 0 & 10 & 10 & 20 & 0 & 20 & 5 & 8 & $\mathbf{1 2}$ & $\mathbf{6}$ & $\mathbf{5}$ & $\mathbf{6}$ & $\mathbf{3 6 0}$ \\
3 & 0 & 10 & 10 & 20 & 0 & 20 & 5 & 8 & $\mathbf{1 2}$ & $\mathbf{5}$ & $\mathbf{6}$ & $\mathbf{6}$ & $\mathbf{3 6 0}$ \\
4 & 0 & 10 & 10 & 20 & 0 & 20 & 5 & 8 & $\mathbf{1 2}$ & $\mathbf{3}$ & $\mathbf{1 0}$ & $\mathbf{6}$ & $\mathbf{3 6 0}$ \\
5 & 0 & 10 & 10 & 20 & 0 & 20 & 5 & 8 & $\mathbf{1 3}$ & $\mathbf{4}$ & $\mathbf{7}$ & $\mathbf{2}$ & $\mathbf{3 6 4}$ \\
6 & 0 & 10 & 10 & 20 & 0 & 20 & 5 & 8 & $\mathbf{1 5}$ & $\mathbf{4}$ & $\mathbf{6}$ & $\mathbf{6}$ & $\mathbf{3 6 0}$ \\
7 & 0 & 10 & 10 & 20 & 0 & 20 & 5 & 8 & $\mathbf{1 5}$ & $\mathbf{3}$ & $\mathbf{8}$ & $\mathbf{6}$ & $\mathbf{3 6 0}$ \\
8 & 0 & 10 & 10 & 20 & 0 & 20 & 5 & 8 & $\mathbf{1 8}$ & $\mathbf{4}$ & $\mathbf{5}$ & $\mathbf{6}$ & $\mathbf{3 6 0}$ \\
9 & 0 & 10 & 10 & 20 & 0 & 20 & 5 & 8 & $\mathbf{2 0}$ & $\mathbf{3}$ & $\mathbf{6}$ & $\mathbf{6}$ & $\mathbf{3 6 0}$ \\
\hline
\end{tabular}




\subsection{Case Study of a Calendar with 13 Months, 4 Weeks and 7 days (M13W4D7+R2)}

In this paper, only the perennial calendar "M13W4D7+R2" (option 5) is discussed, while others can be interpreted in the same way. Table 3 presents the proposed perennial calendar "M13W4D7+R2" based on some new rules, as stated below:

- One year has 13 months with an exact number of days and weeks. No days are added to any month nor to any week. Hence, the problem (a) mentioned in section 1.2 is resolved.

- Each month has exactly 4 weeks

- Each week has exactly 7 days. Therefore, the total number of days in a year becomes equal to 364 ( 7 days $\times 4$ weeks $\times 13$ months)

- A new month is added to the list, which is called "Month Zero", in which it contains the remaining days (Year-day and the Leap-day). The reason for adding this month is to separate the remaining days from the normal days, which is not the case of IFC. In addition, it respects the international standard ISO 8601 in which the dates are expressed. For example, 2020-00-01 is the Year-day, 2020-00-02 is the leap-day in a leap year, 2020-01-01 is the first official day of the year 2020, which is Monday, etc. Therefore, there is a consistency in numbering the days, dates, and their expressions.

- We do not celebrate the end of a year as other existing calendars do, such as the GC, JC, and IFC. On the contrary, we celebrate the beginning of a new year. That is why the Month Zero is added at the beginning, which represents a new start and a happy month in our lives. This method has a positive impact on the psychology of the people in which the end is not important as the beginning of a new thing in their life.

- Friday will never occur on the $13^{\text {th }}$ of any month. Therefore, some people who feel pessimistic about this date will be satisfied with the new calendar. Hence, the problem (e) in section 1.2 is solved.

- The Year-Day and Leap-Day only belong to the "Month Zero". Therefore, months still have the same number of days and will never change. Therefore, the problem (d) in section 1.2 is solved.

- A leap year has 366 days, and its occurrence follows the Gregorian rules.

- Each week starts on Monday and ends on Sunday, which agrees with the international standard ISO 8601. Therefore, the problems (c) and (f) in section 1.2 are answered.

- Each month starts on Monday and ends on a Sunday.

- Every year starts on Monday and ends on Sunday. Therefore, Month Zero is considered as a fictive month with a maximum of 2 days, which are feast days that celebrate the beginning of a new year.

- For business purpose, instead of dividing the year into quarters or triannuals, it is recommended to consider weeks which give more accurate results. For example, if we want to divide a year into 4 quarters, in the proposed calendar, each quarter is exactly 13 weeks. For a triannual year, 17 weeks are considered for the first two triannually based year, and 18 weeks are considered for the third period. Therefore, the problem (b) mentioned in section 1.2 is resolved. 
Table 3: Output Results of the Optimization Model.

The proposed Perennial Calendar M13W4D7+R2

Year: Any year has the same sequence of days and dates

\begin{tabular}{|c|c|}
\hline \multicolumn{2}{|c|}{ Month Zero } \\
\hline Year-day & Leap-day \\
\hline 1 & 2 \\
\hline
\end{tabular}

Month 1 (January)

Mon Tue Wed Thu Fri Sat Sun

\begin{tabular}{|c|c|c|c|c|c|c|}
\hline 1 & 2 & 3 & 4 & 5 & 6 & 7 \\
\hline 8 & 9 & 10 & 11 & 12 & 13 & 14 \\
\hline 15 & 16 & 17 & 18 & 19 & 20 & 21 \\
\hline 22 & 23 & 24 & 25 & 26 & 27 & 28 \\
\hline
\end{tabular}

\begin{tabular}{|c|c|c|c|c|c|c|}
\hline \multicolumn{7}{|c|}{ Month 2 (February) } \\
\hline Mon & Tue & Wed & Thu & Fri & Sat & Sun \\
\hline 1 & 2 & 3 & 4 & 5 & 6 & 7 \\
\hline 8 & 9 & 10 & 11 & 12 & 13 & 14 \\
\hline 15 & 16 & 17 & 18 & 19 & 20 & 21 \\
\hline 22 & 23 & 24 & 25 & 26 & 27 & 28 \\
\hline
\end{tabular}

\begin{tabular}{|c|c|c|c|c|c|c|}
\hline \multicolumn{7}{|c|}{ Month 4 (April) } \\
\hline Mon & Tue & Wed & Thu & Fri & Sat & Sun \\
\hline 1 & 2 & 3 & 4 & 5 & 6 & 7 \\
\hline 8 & 9 & 10 & 11 & 12 & 13 & 14 \\
\hline 15 & 16 & 17 & 18 & 19 & 20 & 21 \\
\hline 22 & 23 & 24 & 25 & 26 & 27 & 28 \\
\hline
\end{tabular}

\begin{tabular}{|c|c|c|c|c|c|c|}
\hline \multicolumn{7}{|c|}{ Month 6 (June) } \\
\hline Mon & Tue & Wed & Thu & Fri & Sat & Sun \\
\hline 1 & 2 & 3 & 4 & 5 & 6 & 7 \\
\hline 8 & 9 & 10 & 11 & 12 & 13 & 14 \\
\hline 15 & 16 & 17 & 18 & 19 & 20 & 21 \\
\hline 22 & 23 & 24 & 25 & 26 & 27 & 28 \\
\hline
\end{tabular}

\begin{tabular}{|c|c|c|c|c|c|c|}
\hline \multicolumn{7}{|c|}{ Month 8 (August) } \\
\hline Mon & Tue & Wed & Thu & Fri & Sat & Sun \\
\hline 1 & 2 & 3 & 4 & 5 & 6 & 7 \\
\hline 8 & 9 & 10 & 11 & 12 & 13 & 14 \\
\hline 15 & 16 & 17 & 18 & 19 & 20 & 21 \\
\hline 22 & 23 & 24 & 25 & 26 & 27 & 28 \\
\hline
\end{tabular}

\begin{tabular}{|c|c|c|c|c|c|c|}
\hline \multicolumn{7}{|c|}{ Month 10 (October) } \\
\hline Mon & Tue & Wed & Thu & Fri & Sat & Sun \\
\hline 1 & 2 & 3 & 4 & 5 & 6 & 7 \\
\hline 8 & 9 & 10 & 11 & 12 & 13 & 14 \\
\hline 15 & 16 & 17 & 18 & 19 & 20 & 21 \\
\hline 22 & 23 & 24 & 25 & 26 & 27 & 28 \\
\hline
\end{tabular}

\begin{tabular}{|c|c|c|c|c|c|c|}
\hline \multicolumn{7}{|c|}{ Month 12 (December) } \\
\hline Mon & Tue & Wed & Thu & Fri & Sat & Sun \\
\hline 1 & 2 & 3 & 4 & 5 & 6 & 7 \\
\hline 8 & 9 & 10 & 11 & 12 & 13 & 14 \\
\hline 15 & 16 & 17 & 18 & 19 & 20 & 21 \\
\hline 22 & 23 & 24 & 25 & 26 & 27 & 28 \\
\hline
\end{tabular}

\begin{tabular}{|c|c|c|c|c|c|c|}
\hline \multicolumn{7}{|c|}{ Month 3 (March) } \\
\hline Mon & Tue & Wed & Thu & Fri & Sat & Sun \\
\hline 1 & 2 & 3 & 4 & 5 & 6 & 7 \\
\hline 8 & 9 & 10 & 11 & 12 & 13 & 14 \\
\hline 15 & 16 & 17 & 18 & 19 & 20 & 21 \\
\hline 22 & 23 & 24 & 25 & 26 & 27 & 28 \\
\hline
\end{tabular}

\begin{tabular}{|c|c|c|c|c|c|c|}
\hline \multicolumn{7}{|c|}{ Month 5 (May) } \\
\hline Mon & Tue & Wed & Thu & Fri & Sat & Sun \\
\hline 1 & 2 & 3 & 4 & 5 & 6 & 7 \\
\hline 8 & 9 & 10 & 11 & 12 & 13 & 14 \\
\hline 15 & 16 & 17 & 18 & 19 & 20 & 21 \\
\hline 22 & 23 & 24 & 25 & 26 & 27 & 28 \\
\hline
\end{tabular}

\begin{tabular}{|c|c|c|c|c|c|c|}
\hline \multicolumn{7}{|c|}{ Month 7 (July) } \\
\hline Mon & Tue & Wed & Thu & Fri & Sat & Sun \\
\hline 1 & 2 & 3 & 4 & 5 & 6 & 7 \\
\hline 8 & 9 & 10 & 11 & 12 & 13 & 14 \\
\hline 15 & 16 & 17 & 18 & 19 & 20 & 21 \\
\hline 22 & 23 & 24 & 25 & 26 & 27 & 28 \\
\hline
\end{tabular}

\begin{tabular}{|c|c|c|c|c|c|c|}
\hline \multicolumn{7}{|c|}{ Month 9 (September) } \\
\hline Mon & Tue & Wed & Thu & Fri & Sat & Sun \\
\hline 1 & 2 & 3 & 4 & 5 & 6 & 7 \\
\hline 8 & 9 & 10 & 11 & 12 & 13 & 14 \\
\hline 15 & 16 & 17 & 18 & 19 & 20 & 21 \\
\hline 22 & 23 & 24 & 25 & 26 & 27 & 28 \\
\hline
\end{tabular}

\begin{tabular}{|c|c|c|c|c|c|c|}
\hline \multicolumn{7}{|c|}{ Month 11 (November) } \\
\hline Mon & Tue & Wed & Thu & Fri & Sat & Sun \\
\hline 1 & 2 & 3 & 4 & 5 & 6 & 7 \\
\hline 8 & 9 & 10 & 11 & 12 & 13 & 14 \\
\hline 15 & 16 & 17 & 18 & 19 & 20 & 21 \\
\hline 22 & 23 & 24 & 25 & 26 & 27 & 28 \\
\hline
\end{tabular}

\begin{tabular}{|c|c|c|c|c|c|c|}
\hline \multicolumn{7}{|c|}{ Month 13 (Undecember) } \\
\hline Mon & Tue & Wed & Thu & Fri & Sat & Sun \\
\hline 1 & 2 & 3 & 4 & 5 & 6 & 7 \\
\hline 8 & 9 & 10 & 11 & 12 & 13 & 14 \\
\hline 15 & 16 & 17 & 18 & 19 & 20 & 21 \\
\hline 22 & 23 & 24 & 25 & 26 & 27 & 28 \\
\hline
\end{tabular}

Based on Table 3, it is clear that the proposed Calendar has a more systematic organization of days and months in a year. The first day of a month always starts on Monday, and the last day of each month is always Sunday. Therefore, counting days becomes an easy task, and there is no need for complex algorithms to predict the days and dates in previous years. The days and dates in the proposed Calendar have strong and correlated relationships, which can be described by simple mathematical equations as in Equation (8). 


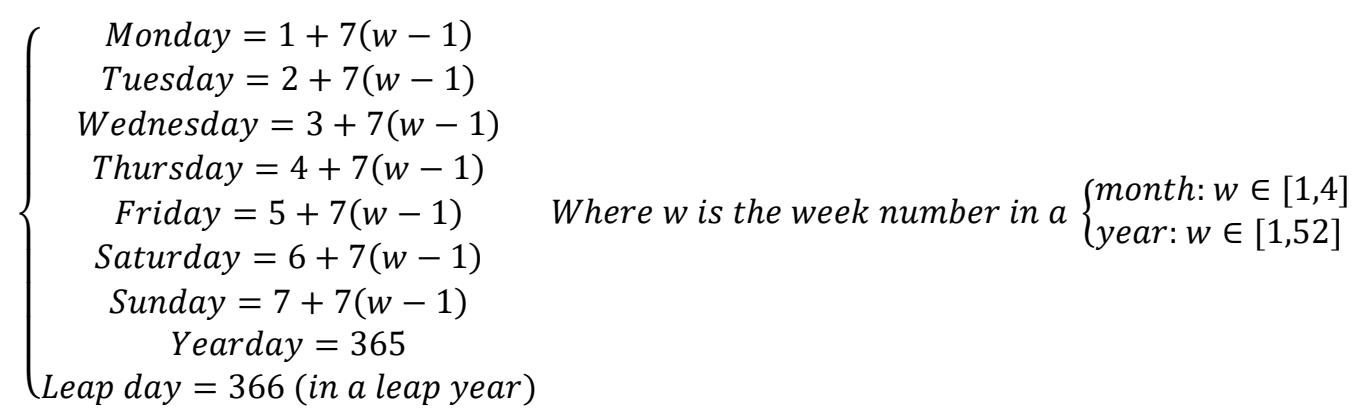

As an example, calculate the date of Monday in the third week of a month.

Answer: Monday $=1+7(3-1)=15$

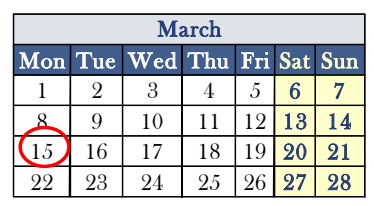

Another example, calculate the day number of Wednesday located on the 36th week of the year. Answer: Wednesday $=3+7(w-1)=3+7(36-1)=248$

\begin{tabular}{|c|c|c|c|c|c|c|}
\hline \multicolumn{7}{|c|}{ July } \\
\hline Mon & Tue & Wed & Thu & Fri & Sat & Sun \\
\hline 169 & 170 & 171 & 172 & 173 & 174 & 175 \\
\hline 176 & 177 & 178 & 179 & 180 & 181 & $\mathbf{1 8 2}$ \\
\hline 183 & 184 & 185 & 186 & 187 & 188 & $\mathbf{1 8 9}$ \\
\hline 190 & 191 & 192 & 193 & 194 & 195 & 196 \\
\hline
\end{tabular}
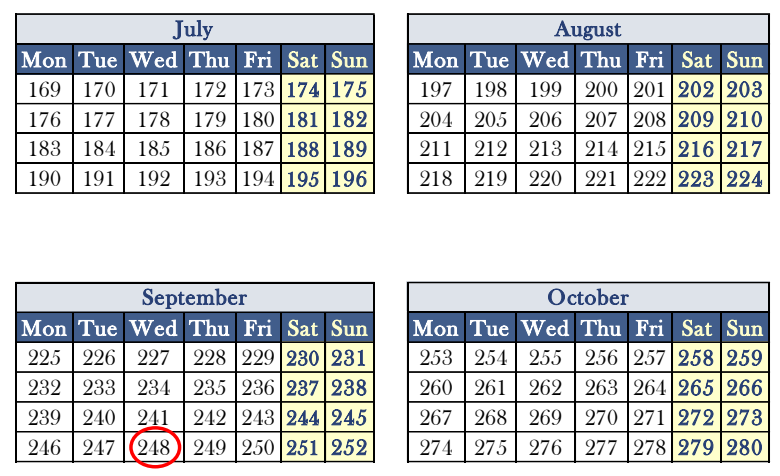

\subsection{Comparison between the proposed calendar and the Gregorian calendar}

In this subsection, a comparison between the proposed and Gregorian calendars is presented. Table 4 shows both calendars, in which it is obvious that the proposed one is much easier to memorize because all months look the same. A more detailed comparison is presented in Table 5. 
Table 4: Comparison between the proposed and Gregorian calendars.

\begin{tabular}{|c|c|c|c|c|c|c|c|c|c|c|c|c|c|c|c|c|c|c|c|c|c|c|c|c|c|c|c|}
\hline \multirow{2}{*}{\multicolumn{14}{|c|}{$\begin{array}{l}\text { The proposed Perennial Calendar M13W4D7+R2 } \\
\text { Year: Any year has the same sequence of days and dates }\end{array}$}} & \multicolumn{14}{|c|}{ Gregorian Calendar } \\
\hline & & & \multicolumn{9}{|c|}{ Year: Any year has the same sequence of days and dates } & & & \multicolumn{14}{|c|}{ Only for the year 2020 , the dispalcement of dates and days change from year to year } \\
\hline \multicolumn{7}{|c|}{ Month Zero } & \multicolumn{7}{|c|}{ Month 1 (January) } & \multicolumn{7}{|c|}{ January 2020} & \multicolumn{7}{|c|}{ February 2020} \\
\hline \multicolumn{3}{|c|}{ Year-day } & & Leap- & -day & & Mon & Tue & Wed & Thu 1 & Fri $S$ & Sat $S$ & Sun & $\operatorname{Sun} \mid \mathbf{N}$ & Mon & Tue & Wed & Thu & Fri|s & Sat & Sun & Mon & Tue & Wed & Thu $\mid$ & Fri| & Sat \\
\hline & 1 & & & 2 & & & 1 & $2 \mid$ & 3 & 4 & 5 & 6 & 7 & & & & 1 & 2 & 3 & 4 & & & & & & & 1 \\
\hline & & & & & & & 8 & 9 & 10 & 11 & 12 12 12 & 13 & 14 & 5 & 6 & 7 & 8 & 9 & 10 & 11 & 2 & 3 & 4 & 5 & 6 & 7 & 8 \\
\hline & & & & & & & 15 & 16 & 17 & 18 & 192 & 20 & 21 & 12 & 13 & 14 & 15 & 16 & 17 & 18 & 9 & 10 & 11 & 12 & 13 & 14 & 15 \\
\hline & & & & & & & 22 & 23 & 24 & 25 & \begin{tabular}{l|l}
26 & 2
\end{tabular} & \begin{tabular}{l|l|l}
27 & 2 \\
\end{tabular} & 28 & 19 & 20 & 21 & 22 & 23 & 24 & 25 & 16 & 17 & 18 & 19 & 20 & 21 & 22 \\
\hline & & & & & & & & & & & & & & 26 & 27 & 28 & 29 & 30 & 31 & & 23 & 24 & 25 & 26 & 27 & 28 & 29 \\
\hline & Mor & nth 2 & (Febr & cuary & & & & & onth 3 & (Mar & rch) & & & & & $\mathrm{Ma}$ & $\operatorname{rch} 20$ & 020 & & & & & & ril 20 & 20 & & \\
\hline Mon & Tue & Wed & Thu & Fri & Sat $\mathbf{S}$ & Sun & Mon & Tue & Wed & Thu & Fris & \begin{tabular}{l|l} 
Sat & S
\end{tabular} & Sun & $\operatorname{Sun} \mid \mathbf{M}$ & Mon & Tue & Wed & $\mid$ Thu $\mid$ & Fri $\mid \mathrm{s}$ & Sat & Sun & Mon | & Tue & Wed & $\mid$ Thu $\mid$ & Fri & Sat \\
\hline \begin{tabular}{l|l} 
\\
\end{tabular} & \begin{tabular}{|l|}
2 \\
\end{tabular} & 3 & \begin{tabular}{|l|}
4 \\
\end{tabular} & \begin{tabular}{|l|l|}
5 \\
\end{tabular} & \begin{tabular}{l|l}
6 & \\
\end{tabular} & 7 & 1 & \begin{tabular}{|l|l}
2 \\
\end{tabular} & 3 & \begin{tabular}{|l|}
4 \\
\end{tabular} & \begin{tabular}{|l|l|}
5 & \\
\end{tabular} & \begin{tabular}{l|l}
6 & \\
\end{tabular} & 7 & 1 & 2 & 3 & 4 & 5 & 6 & 7 & & & & 1 & 2 & 3 & 4 \\
\hline 8 & 9 & 10 & 11 & 12 & \begin{tabular}{|l|}
13 \\
\end{tabular} & 14 & 8 & 9 & 10 & 11 & \begin{tabular}{l|l}
12 & 1 \\
\end{tabular} & \begin{tabular}{l|l}
13 & 1 \\
\end{tabular} & 14 & 8 & 9 & 10 & 11 & 12 & 13 & 14 & 5 & 6 & 7 & 8 & 9 & 10 & 11 \\
\hline 15 & 16 & 17 & 18 & \begin{tabular}{l|l}
19 \\
\end{tabular} & 20 & 21 & 15 & 16 & 17 & 18 & \begin{tabular}{l|l}
19 & 2
\end{tabular} & 20 & 21 & 15 & 16 & 17 & 18 & 19 & 20 & 21 & 12 & 13 & 14 & 15 & 16 & 17 & 18 \\
\hline 22 & 23 & 24 & 25 & \begin{tabular}{l|l}
26 \\
\end{tabular} & \begin{tabular}{l|l|}
27 \\
\end{tabular} & 28 & 22 & 23 & 24 & 25 & \begin{tabular}{l|l}
26 & \\
\end{tabular} & \begin{tabular}{l|l}
27 & \\
\end{tabular} & 28 & 22 & 23 & 24 & 25 & 26 & 27 & 28 & 19 & 20 & 21 & 22 & 23 & 24 & 25 \\
\hline & & & & & & & & & & & & & & 29 & 30 & 31 & & & & & 26 & 27 & 28 & 29 & 30 & & \\
\hline & & Ionth & $4(\mathrm{Ap}$ & & & & & & Ionth & $5 \mathrm{Ma}$ & & & & & & & ay 202 & & & & & & & ne 202 & & & \\
\hline Mon & Tue & Wed & Thu & Fri & Sat 1 & Sun & Mon & Tue & Wed & Thu I & Fri $S$ & $\begin{array}{l}\text { Sat } \\
\end{array}$ & Sun & $\operatorname{Sun} \mid 1$ & Mon & Tue & Wed & Thu $\mid$ & Fri $\mid \mathrm{s}$ & Sat & Sun & Mon & Tue & Wed & Thu $\mid \mathbf{I}$ & Fri & Sat \\
\hline \begin{tabular}{l|l}
1 \\
\end{tabular} & \begin{tabular}{|l|}
2 \\
\end{tabular} & 3 & 4 & \begin{tabular}{|l|}
5 \\
\end{tabular} & \begin{tabular}{l|l}
6 & \\
\end{tabular} & 7 & 1 & \begin{tabular}{|l|}
2 \\
\end{tabular} & 3 & \begin{tabular}{|l|l}
4 & \\
\end{tabular} & \begin{tabular}{|l|l}
5 & \\
\end{tabular} & \begin{tabular}{l|l}
6 & \\
\end{tabular} & 7 & & & & & & 1 & 2 & & 1 & 2 & 3 & 4 & 5 & 6 \\
\hline 8 & 9 & 10 & 11 & 12 & \begin{tabular}{l|l}
13 \\
\end{tabular} & 14 & 8 & 9 & 10 & 11 & \begin{tabular}{l|l}
12 & 1 \\
\end{tabular} & 13 & 14 & 3 & 4 & 5 & 6 & 7 & 8 & 9 & 7 & 8 & 9 & 10 & 11 & 12 & 13 \\
\hline 15 & 16 & 17 & 18 & \begin{tabular}{l|l}
19 \\
\end{tabular} & 20 & 21 & 15 & 16 & 17 & 18 & \begin{tabular}{l|l}
19 & 2 \\
\end{tabular} & 20 & 21 & 10 & 11 & 12 & 13 & 14 & 15 & 16 & 14 & 15 & 16 & 17 & 18 & 19 & 20 \\
\hline 22 & 23 & 24 & \begin{tabular}{l|l}
25 \\
\end{tabular} & \begin{tabular}{|l|}
26 \\
\end{tabular} & \begin{tabular}{l|l}
27 \\
\end{tabular} & 28 & 22 & 23 & 24 & 25 & \begin{tabular}{l|l}
26 & 2 \\
\end{tabular} & \begin{tabular}{l|l}
27 & 2 \\
\end{tabular} & 28 & 17 & 18 & 19 & 20 & 21 & 22 & 23 & 21 & 22 & 23 & 24 & 25 & 26 & 27 \\
\hline & & & & & & & & & & & & & & 24 & 25 & 26 & 27 & 28 & 29 & 30 & 28 & 29 & 30 & & & & \\
\hline & & & & & & & & & & & & & & 31 & & & & & & & & & & & & & \\
\hline & & Ionth & 6 (Jur & & & & & & Ionth & $7 \mathrm{OJul}$ & & & & & & & ly 202 & & & & & & Aug & zust 20 & 020 & & \\
\hline Mon & Tue & Wed & Thu & Fri & Sat $S$ & Sun & Mon & Tue & Wed & Thu & Fri S & Sat $S$ & Sun & $\operatorname{Sun} \mid$ & Mon & Tue & Wed & Thu $\mid$ & Fri $\mid s$ & Sat & Sun & Mon & Tue & Wed & Thu $\mid$ & Fri & Sat \\
\hline 1 & 2 & 3 & \begin{tabular}{l|}
4 \\
\end{tabular} & \begin{tabular}{|l|}
5 \\
\end{tabular} & 6 & 7 & 1 & \begin{tabular}{|c|}
2 \\
\end{tabular} & 3 & \begin{tabular}{l|l}
4 \\
\end{tabular} & 5 & \begin{tabular}{l|l}
6 & \\
\end{tabular} & 7 & & & & 1 & 2 & 3 & 4 & & & & & & & 1 \\
\hline 8 & 9 & 10 & 11 & \begin{tabular}{|l|}
12 \\
\end{tabular} & \begin{tabular}{|l|l|}
13 \\
\end{tabular} & 14 & 8 & 9 & 10 & 11 & \begin{tabular}{l|l}
12 & 1 \\
\end{tabular} & 13 & 14 & 5 & 6 & 7 & 8 & 9 & 10 & 11 & 2 & 3 & 4 & 5 & 6 & 7 & 8 \\
\hline 15 & 16 & 17 & 18 & \begin{tabular}{|l|}
19 \\
\end{tabular} & 20 & 21 & 15 & 16 & 17 & 18 & \begin{tabular}{l|l}
19 & 2 \\
\end{tabular} & \begin{tabular}{l|l}
20 & 2 \\
\end{tabular} & 21 & 12 & 13 & 14 & 15 & 16 & 17 & 18 & 9 & 10 & 11 & 12 & 13 & 14 & 15 \\
\hline 22 & 23 & 24 & 25 & \begin{tabular}{|l|}
26 \\
\end{tabular} & 27 & 28 & 22 & 23 & 24 & 25 & \begin{tabular}{|l|l}
26 & 2 \\
\end{tabular} & \begin{tabular}{|l|l}
27 & 2 \\
\end{tabular} & 28 & 19 & 20 & 21 & 22 & 23 & 24 & 25 & 16 & 17 & 18 & 19 & 20 & 21 & 22 \\
\hline & & & & & & & & & & & & & & 26 & 27 & 28 & 29 & 30 & 31 & & 23 & 24 & 25 & 26 & 27 & 28 & 29 \\
\hline & & & & & & & & & & & & & & & & & & & & & 30 & 31 & & & & & \\
\hline & & onth 8 & (Aug & gust) & & & & Mon & th 9 ( & Septer & ember & & & & & Septe & ember & 2020 & & & & & Octo & ber 2 & 2020 & & \\
\hline Mon & Tue & Wed & Thu & Fri & Sat $S$ & Sun & Mon & Tue & Wed & Thu I & Fri S & Sat $S$ & Sun & $\left.\operatorname{Sun}\right|_{1}$ & Mon & Tue & Wed & Thu $\mid$ & Fri|s & Sat & Sun & Mon & Tue & Wed & Thu $\mid$ & Fri| & Sat \\
\hline 1 & \begin{tabular}{|l|}
2 \\
\end{tabular} & 3 & 4 & \begin{tabular}{|l|}
5 \\
\end{tabular} & \begin{tabular}{l|l}
6 & \\
\end{tabular} & 7 & 1 & \begin{tabular}{|l|}
2 \\
\end{tabular} & 3 & 4 & \begin{tabular}{|l|l}
5 & \\
\end{tabular} & \begin{tabular}{l|l}
6 & \\
\end{tabular} & 7 & & & 1 & 2 & 3 & 4 & 5 & & & & & 1 & 2 & 3 \\
\hline 8 & 9 & 10 & 11 & 12 & \begin{tabular}{l|l}
13 \\
\end{tabular} & 14 & 8 & 9 & 10 & 11 & \begin{tabular}{|l|l}
12 & 1 \\
\end{tabular} & \begin{tabular}{l|l}
13 & 1 \\
\end{tabular} & 14 & 6 & 7 & 8 & 9 & 10 & 11 & 12 & 4 & 5 & 6 & 7 & 8 & 9 & 10 \\
\hline 15 & 16 & 17 & 18 & \begin{tabular}{|l|}
19 \\
\end{tabular} & 20 & 21 & 15 & 16 & 17 & 18 & \begin{tabular}{|l|l}
19 & 2 \\
\end{tabular} & \begin{tabular}{l|l}
20 & 2 \\
\end{tabular} & 21 & 13 & 14 & 15 & 16 & 17 & 18 & 19 & 11 & 12 & 13 & 14 & 15 & 16 & 17 \\
\hline 22 & 23 & 24 & 25 & \begin{tabular}{|l|}
26 \\
\end{tabular} & 27 & 28 & 22 & 23 & 24 & 25 & \begin{tabular}{|l|l}
26 & 2 \\
\end{tabular} & \begin{tabular}{l|l}
27 & 2 \\
\end{tabular} & 28 & 20 & 21 & 22 & 23 & 24 & 25 & 26 & 18 & 19 & 20 & 21 & 22 & 23 & 24 \\
\hline & & & & & & & & & & & & & & 27 & 28 & 29 & 30 & & & & 25 & 26 & 27 & 28 & 29 & 30 & 31 \\
\hline & Mon & nth 10 & (Oct & tober & & & & Mont & h 11 & (Nove & embe & & & & & Nove & ember 2 & 2020 & & & & & Dece & mber 2 & 2020 & & \\
\hline Mon & Tue & Wed & Thu & Fri & Sat & Sun & Mon & Tue & Wed & Thu & Fri & \begin{tabular}{l|l} 
Sat & $S$
\end{tabular} & Sun & Sun 1 & Mon & Tue & Wed & $\mid$ Thu & Fri|s & Sat & Sun & Mon & Tue & Wed & Thu & Fri & Sat \\
\hline 1 & \begin{tabular}{|c|}
2 \\
\end{tabular} & 3 & 4 & \begin{tabular}{|c|}
5 \\
\end{tabular} & 6 & 7 & 1 & \begin{tabular}{|c|}
2 \\
\end{tabular} & 3 & 4 & 5 & 6 & 7 & 1 & 2 & 3 & 4 & 5 & 6 & 7 & & & 1 & 2 & 3 & 4 & 5 \\
\hline 8 & 9 & 10 & 11 & 12 & 13 & 14 & 8 & 9 & 10 & 11 & \begin{tabular}{|l|l}
12 & 1 \\
\end{tabular} & \begin{tabular}{l|l}
13 & 1 \\
\end{tabular} & 14 & 8 & 9 & 10 & 11 & 12 & 13 & 14 & 6 & 7 & 8 & 9 & 10 & 11 & 12 \\
\hline 15 & 16 & 17 & 18 & 19 & 20 & 21 & 15 & 16 & 17 & 18 & \begin{tabular}{|l|l}
19 & 2 \\
\end{tabular} & \begin{tabular}{l|l}
20 & 2 \\
\end{tabular} & 21 & 15 & 16 & 17 & 18 & 19 & 20 & 21 & 13 & 14 & 15 & 16 & 17 & 18 & 19 \\
\hline 22 & 23 & 24 & 25 & \begin{tabular}{|l|}
26 \\
\end{tabular} & 27 & 28 & 22 & 23 & 24 & 25 & \begin{tabular}{|l|l}
26 & 2 \\
\end{tabular} & \begin{tabular}{l|l}
27 & 2 \\
\end{tabular} & 28 & 22 & 23 & 24 & 25 & 26 & 27 & 28 & 20 & 21 & 22 & 23 & 24 & 25 & 26 \\
\hline & & & & & & & & & & & & & & 29 & 30 & & & & & & 27 & 28 & 29 & 30 & 31 & & \\
\hline & Mont & th 12 & (Dece & embe & & & & Month & 13 (L & Undec & cemb & & & & & & & & & & & & & & & & \\
\hline Mon & Tue & Wed & Thu & Fri & Sat S & Sun & Mon & Tue & Wed & Thu & Fri S & \begin{tabular}{l|l} 
Sat & .
\end{tabular} & Sun & & & & & & & & & & & & & & \\
\hline 1 & \begin{tabular}{|c|}
2 \\
\end{tabular} & 3 & 4 & \begin{tabular}{|c|}
5 \\
\end{tabular} & 6 & 7 & \begin{tabular}{|l|}
1 \\
\end{tabular} & \begin{tabular}{|c|}
2 \\
\end{tabular} & 3 & 4 & 5 & 6 & 7 & & & & & & & & & & & & & & \\
\hline 8 & 9 & 10 & 11 & \begin{tabular}{|l|}
12 \\
\end{tabular} & 13 & 14 & 8 & 9 & 10 & 11 & \begin{tabular}{|l|l}
12 & 1 \\
\end{tabular} & \begin{tabular}{l|l}
13 & 1 \\
\end{tabular} & 14 & & & & & & & & & & & & & & \\
\hline 15 & 16 & 17 & 18 & 19 & 20 & 21 & 15 & 16 & 17 & 18 & \begin{tabular}{l|l}
19 & 2 \\
\end{tabular} & \begin{tabular}{l|l}
20 & 2 \\
\end{tabular} & 21 & & & & & & & & & & & & & & \\
\hline 22 & 23 & 24 & 25 & \begin{tabular}{|l|}
26 \\
\end{tabular} & 27 & 28 & 22 & 23 & 24 & 25 & \begin{tabular}{|l|l}
26 & \\
\end{tabular} & \begin{tabular}{l|l}
27 & \\
\end{tabular} & 28 & & & & & & & & & & & & & & \\
\hline
\end{tabular}


Table 5: Comparison between three calendars, the proposed one, Gregorian, and IFC

\begin{tabular}{|c|c|c|c|c|}
\hline Aspects & Description & $\begin{array}{l}\text { Proposed } \\
\text { Calendar }\end{array}$ & $\begin{array}{l}\text { Gregorian } \\
\text { Calendar }\end{array}$ & IFC \\
\hline \multirow[t]{8}{*}{ Technical } & Number of weekends in a year & Up to 106 & Up to 104 & Up to 106 \\
\hline & Complexity of the system & Very easy & Complex & Easy \\
\hline & Computation time & Very low & $\begin{array}{l}\text { Very high } \\
\quad[16]\end{array}$ & Low \\
\hline & Reduce wasted time to check days and dates on a calendar & Very low & Very high & Low \\
\hline & Do we need a Calendar to check the dates & No & Yes & No \\
\hline & Considered as Perennial Calendar & Yes & No & Yes \\
\hline & $\begin{array}{l}\text { The date of days does not change (e.g., the } 17 \text { th always } \\
\text { falls on a Tuesday) }\end{array}$ & Yes & No & Yes \\
\hline & Calendar respects international standards & Yes & No & No \\
\hline \multirow[t]{5}{*}{ Economic } & Number of payable months & 13 & 12 & 13 \\
\hline & $\begin{array}{l}\text { Easy scheduling for institutions and industries with } \\
\text { extended production cycles }\end{array}$ & Yes & No & Yes \\
\hline & $\begin{array}{l}\text { Accurate statistical comparisons by months, since all } \\
\text { months have exactly the same number of business days } \\
\text { and weekends }\end{array}$ & Yes & No & Yes \\
\hline & $\begin{array}{l}\text { Possibility of error in printing the calendar and calculating } \\
\text { the dates }\end{array}$ & No & Yes [17] & No \\
\hline & $\begin{array}{l}\text { Can be considered as a financial calendar in which years } \\
\text { can be divided into quarters, triannuals, and biannuals }\end{array}$ & $\begin{array}{l}\text { Yes (based on } \\
\text { weeks instead } \\
\text { of months) }\end{array}$ & Yes & No \\
\hline \multicolumn{2}{|c|}{ EnvironmentalEco-friendly } & Yes & No & Yes \\
\hline & Reduce the number of printed hard-copies & Yes & No & Yes \\
\hline & Reduce pollution and waste from printing the calendars & Yes & No & Yes \\
\hline & Reduce energy consumption & Yes & No & Yes \\
\hline \multirow[t]{2}{*}{ Individual } & Better organization of personal life & Yes & No & Yes \\
\hline & Accurate appointments and events & Yes & No & Yes \\
\hline \multirow[t]{3}{*}{ Social } & $\begin{array}{l}\text { Movable holidays celebrated on the } n \text {th certain weekday } \\
\text { of a month, (e.g., Thanksgiving Day), would be able to } \\
\text { have a fixed date while keeping their traditional weekday }\end{array}$ & Yes & No & Yes \\
\hline & Better organization of social activities & Yes & No & Yes \\
\hline & $\begin{array}{l}\text { Less conflict because of missing some events, meetings, } \\
\text { and appointments }\end{array}$ & Yes & No & Yes \\
\hline
\end{tabular}

For instance, just to show the importance of the proposed calendar in reducing the pollution, we want to calculate the wasted energy by checking the date and day for each person on Earth. Let us suppose the following assumptions:

- Population worldwide is about 7.8 billion people in 2020,

- Each person as a mobile with a battery capacity of about 10.78Wh (Similar to the Samsung Galaxy),

- The charging efficiency of the mobile is about $92 \%$, 
- Efficiency of the lines and cables from the power utility and homes is about $70 \%$,

- We suppose that the power generation is renewable energy based on photovoltaic systems with an efficiency of about $12 \%$,

Steps:

a. The needed energy to charge the mobile for a day is equal to $(10.78 \mathrm{Wh} /(0.92 \times 0.7 \times 0.12))=$ $140 \mathrm{Wh} /$ day.

b. We consider that each person spend about 1 minute every day just to check the calendar, the dates and days. Therefore, the total energy spent per day just to check the calendar is equal to $140 \mathrm{Wh} /$ day $/ 24 \mathrm{~h} /$ day $/ 60 \mathrm{~min} / \mathrm{h}$ ) $=0.0972 \mathrm{Wh} /$ day

c. The needed energy to check the calendar for the total population per day is equal to $(0.0972 \mathrm{Wh} /$ day $\times 7.8$ billion people $)=758,333,333.3 \mathrm{Wh} /$ day $=758.333 \mathrm{MWh} /$ day,

d. The needed energy to check the calendar for the total population in a year is equal to (758.333 $\mathrm{MWh} /$ day x 365 day/year) $=276.792 \mathrm{GWh} /$ year

Therefore, almost $276.8 \mathrm{GWh} /$ year are wasted just to check the Gregorian calendar, while this huge amount of energy can be saved for something else. Therefore, the advantage of our proposed calendar system is to minimize as possible the wasted time, energy and conflict.

\subsection{Other proposed Calendars}

In the previous subsection, the proposed calendar "M13W4D7+R2" is discussed. However, Table 2 shows other possible solutions, in which some of them will be presented briefly in this subsection. In Table 6 only 4 calendars are presented, which come from Table 2. The yellow boxes represent the weekends and the day offs, and the white boxes are for the working days. 
Table 6: Proposed calendars: (a) M12W5D6+R6, (b) M12W6D5+R6, (c) M10W6D6+R6, and (d) M15W3D8+R6.

(a)

\begin{tabular}{|c|c|c|c|c|c|c|c|c|c|c|c|}
\hline \multicolumn{12}{|c|}{ The proposed Calendar M12W5D6+R6 } \\
\hline \multicolumn{12}{|c|}{ Year: Any year has the same sequence of days and dates } \\
\hline \multicolumn{6}{|c|}{ Month 01} & \multicolumn{6}{|c|}{ Month 02} \\
\hline D1 & $\mathrm{D} 2$ & D3 & $\mathrm{D} 4$ & $\mathrm{D} 5$ & D6 & D1 & $\mathrm{D} 2$ & D3 3 & $\mathrm{D} 4$ & D5 & $\mathrm{D} 6$ \\
\hline 1 & 2 & 3 & 4 & 5 & 6 & 1 & 2 & 3 & 4 & 5 & 6 \\
\hline 7 & 8 & 9 & 10 & 11 & 12 & 7 & 8 & 9 & 10 & 11 & 12 \\
\hline 13 & 14 & 15 & 16 & 17 & 18 & 13 & 14 & 15 & 16 & 17 & 18 \\
\hline 19 & 20 & 21 & 22 & 23 & 24 & 19 & 20 & 21 & 22 & 23 & 24 \\
\hline 25 & 26 & 27 & 28 & 29 & 30 & 25 & 26 & 27 & 28 & 29 & 30 \\
\hline \multicolumn{6}{|c|}{ Month 03} & \multicolumn{6}{|c|}{ Month 04} \\
\hline D1 & D2 & D3 & D4 & D5 & $\mathrm{D} 6$ & D1 & D2 & \begin{tabular}{|l|} 
D3 \\
\end{tabular} & D4 & D5 & $\mathrm{D} 6$ \\
\hline 1 & 2 & 3 & 4 & 5 & 6 & 1 & 2 & 3 & 4 & 5 & 6 \\
\hline 7 & 8 & 9 & 10 & 11 & 12 & 7 & 8 & 9 & 10 & 11 & 12 \\
\hline 13 & 14 & 15 & 16 & 17 & 18 & 13 & 14 & 15 & 16 & 17 & 18 \\
\hline 19 & 20 & 21 & 22 & 23 & 24 & 19 & 20 & 21 & 22 & 23 & 24 \\
\hline 25 & 26 & 27 & 28 & 29 & 30 & 25 & 26 & 27 & 28 & 29 & 30 \\
\hline \multicolumn{6}{|c|}{ Month 05} & \multicolumn{6}{|c|}{ Month 06} \\
\hline D1 & D2 & D3 & D4 & D5 & D6 & D1 & D2 & \begin{tabular}{|l|} 
D3 \\
\end{tabular} & D4 & D5 & $\mathrm{D} 6$ \\
\hline 1 & 2 & 3 & 4 & 5 & 6 & 1 & 2 & 3 & 4 & 5 & 6 \\
\hline 7 & 8 & 9 & 10 & 11 & 12 & 7 & 8 & 9 & 10 & 11 & 12 \\
\hline 13 & 14 & 15 & 16 & 17 & 18 & 13 & 14 & 15 & 16 & 17 & 18 \\
\hline 19 & 20 & 21 & 22 & 23 & 24 & 19 & 20 & 21 & 22 & 23 & 24 \\
\hline 25 & 26 & 27 & 28 & 29 & 30 & 25 & 26 & 27 & 28 & 29 & 30 \\
\hline \multicolumn{6}{|c|}{ Month 07} & \multicolumn{6}{|c|}{ Month 08} \\
\hline D1 & D2 & D3 & D4 & D5 & D6 & D1 & D2 & D3 & D4 & D5 & D6 \\
\hline 1 & 2 & 3 & 4 & 5 & 6 & 1 & 2 & 3 & 4 & 5 & 6 \\
\hline 7 & 8 & 9 & 10 & 11 & 12 & 7 & 8 & 9 & 10 & 11 & 12 \\
\hline 13 & 14 & 15 & 16 & 17 & 18 & 13 & 14 & 15 & 16 & 17 & 18 \\
\hline 19 & 20 & 21 & 22 & 23 & 24 & 19 & 20 & 21 & 22 & 23 & 24 \\
\hline 25 & 26 & 27 & 28 & 29 & 30 & 25 & 26 & 27 & 28 & 29 & 30 \\
\hline \multicolumn{6}{|c|}{ Month 09} & \multicolumn{6}{|c|}{ Month 10} \\
\hline D1 & D2 & D3 & D4 & D5 & D6 & D1 & D2 & D3 & \begin{tabular}{|l|} 
D4 \\
\end{tabular} & D5 & $\mathrm{D} 6$ \\
\hline 1 & 2 & 3 & 4 & 5 & 6 & 1 & 2 & 3 & 4 & 5 & 6 \\
\hline 7 & 8 & 9 & 10 & 11 & 12 & 7 & 8 & 9 & 10 & 11 & 12 \\
\hline 13 & 14 & 15 & 16 & 17 & 18 & 13 & 14 & 15 & 16 & 17 & 18 \\
\hline 19 & 20 & 21 & 22 & 23 & 24 & 19 & 20 & 21 & 22 & 23 & 24 \\
\hline 25 & 26 & 27 & 28 & 29 & 30 & 25 & 26 & 27 & 28 & 29 & 30 \\
\hline \multicolumn{6}{|c|}{ Month 11} & \multicolumn{6}{|c|}{ Month 12} \\
\hline D1 & D2 & D3 & D4 & D5 & D6 & D1 & $\mathrm{D} 2$ & D3 & \begin{tabular}{|l|} 
D4 \\
\end{tabular} & D5 & $\mathrm{D} 6$ \\
\hline 1 & 2 & 3 & 4 & 5 & 6 & 1 & 2 & 3 & 4 & 5 & 6 \\
\hline 7 & 8 & 9 & 10 & 11 & 12 & 7 & 8 & 9 & 10 & 11 & 12 \\
\hline 13 & 14 & 15 & 16 & 17 & 18 & 13 & 14 & 15 & 16 & 17 & 18 \\
\hline 19 & 20 & 21 & 22 & 23 & 24 & 19 & 20 & 21 & 22 & 23 & 24 \\
\hline 25 & 26 & 27 & 28 & 29 & 30 & 25 & 26 & 27 & 28 & 29 & 30 \\
\hline \multicolumn{6}{|c|}{ Month 13 (Year-Month) } & \multirow{2}{*}{\multicolumn{5}{|c|}{$\begin{array}{l}\text { \# of Working Days: } \\
\text { \# of Off Days: }\end{array}$}} & 264 \\
\hline YD1 & YD2 & YD3 & YD4 & YD5 & YD6 & & & & & & 102 \\
\hline 1 & 2 & 3 & 4 & 5 & 6 & $\leftarrow \quad \mathrm{Fc}_{\mathrm{c}}$ & or the & day $36 t$ & 6 in a l & eap ye & \\
\hline
\end{tabular}
the end of the year, an additional Month is added with only 5 days $(+1$ leap day in a leap year). These days are called Yeardays, in which they are different from the normal days, and can be considered as holidays or day off for employees.

(b)

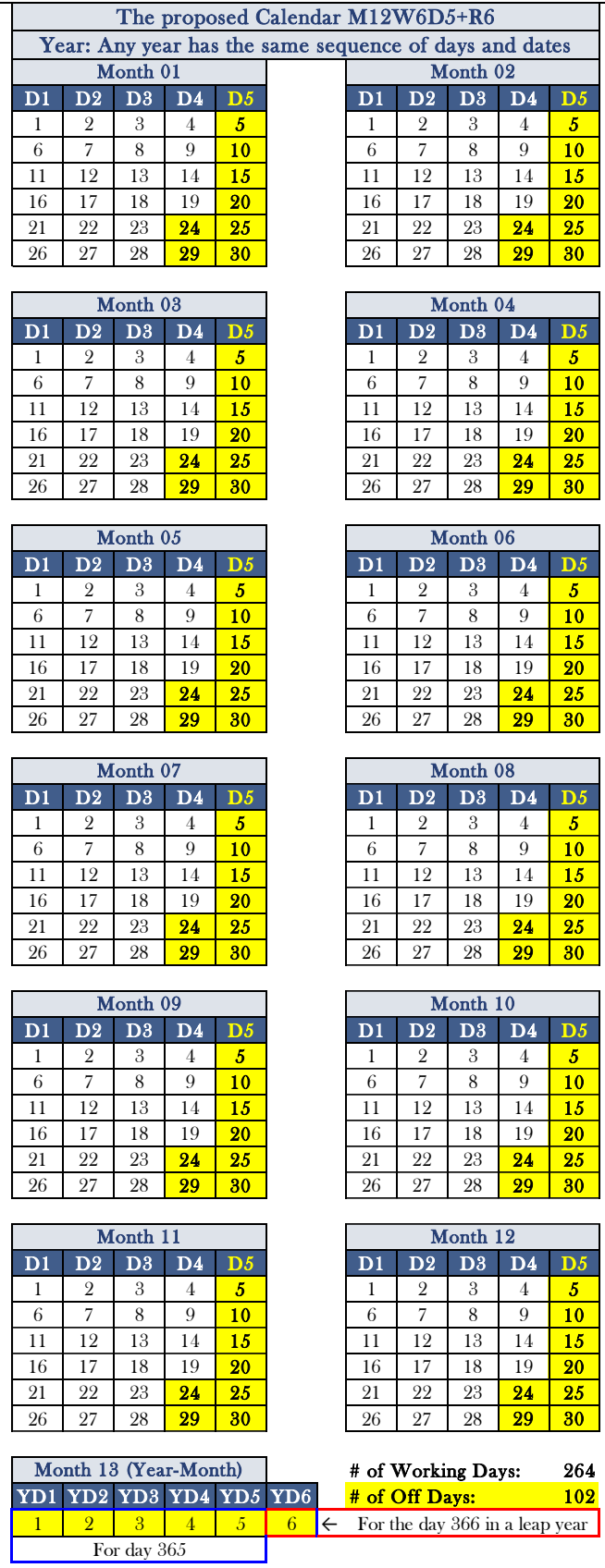

This calendar has 12 official months. Each month has 6 weeks of 5 days each. At the end of the year, an additional Month is added with only 5 day $(+1$ leap day in a leap year). These days are called Yeardays, in which they are different from the normal days, and can be considered as holidays or day off for employees. 
(c)

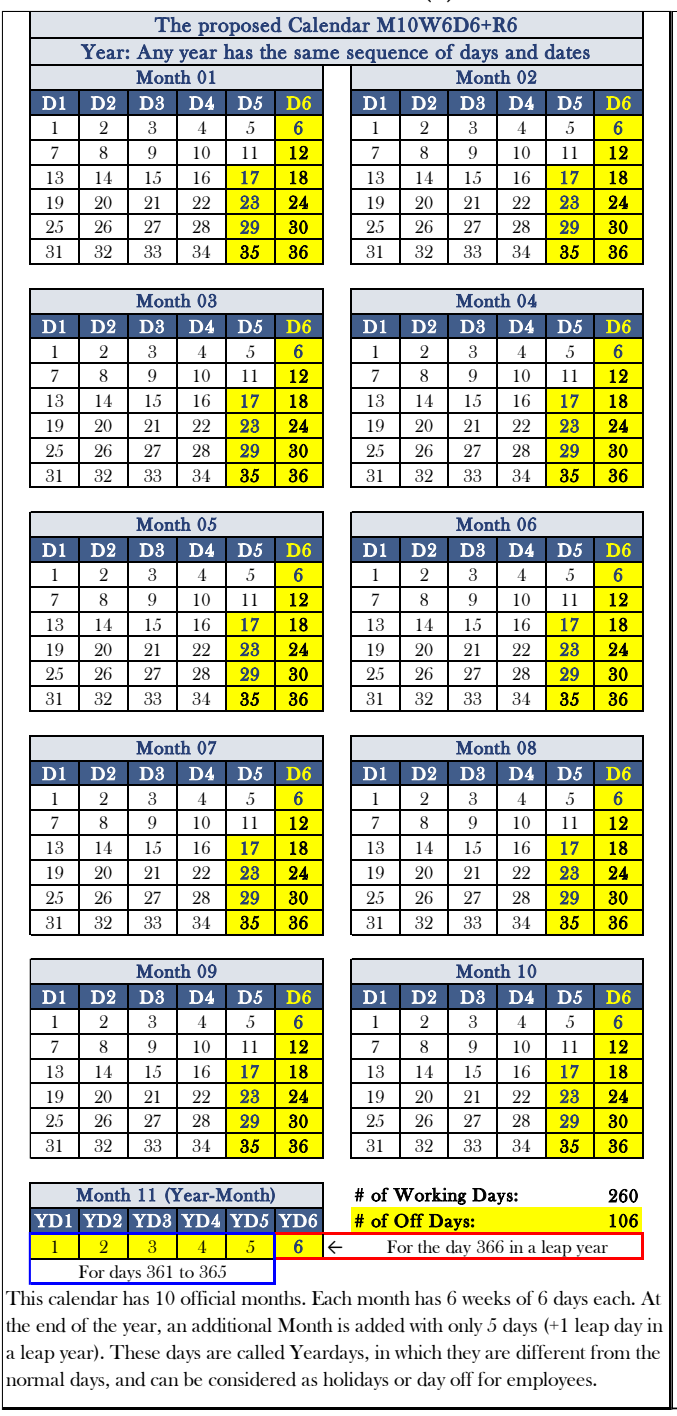

(d)

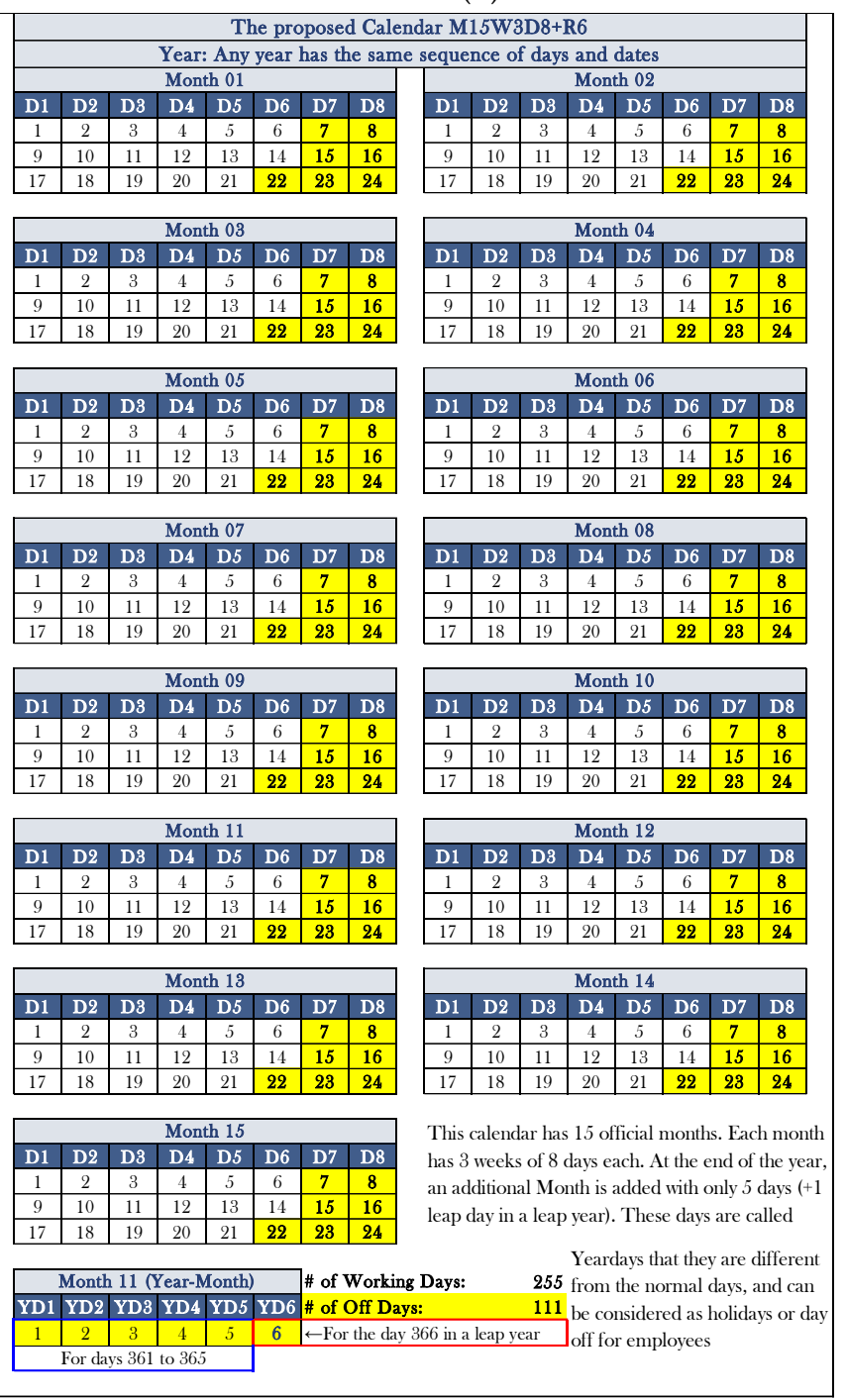

\section{Conclusions}

The Gregorian calendar has been used for several centuries, in which it was introduced to correct the Julian calendar. Despite the success of the Gregorian calendar worldwide, and despite its accuracy, it is not easy to deal with the dates and days and sophisticated software is needed, and billions of hard copies of the calendar are printed every year to help people organize better their life. Thus, millions of trees are cut every year to produce calendars and planners, which increases pollution and the emission of $\mathrm{CO} 2$. To minimize pollution and to go a further step toward a more sustainable society, this paper proposes an original perennial calendar system that is user- and ecofriendly. The proposed calendar system is very easy to interpret and memorize. Thus, there is no need to print hard copies of the calendar; therefore, millions of trees are saved every year, and less pollution is emitted. The proposed calendar system uses optimization algorithms and mathematical modeling in order to obtain the optimal distribution of days, weeks, and months in a year. This paper compared the proposed calendar system with the Gregorian calendar and the International Fixed Calendar. Results show that the proposed one in this paper has more advantages compared to the other ones. Further statistical analysis is required to see how people react regarding the idea of changing the calendar system and what will be the next step to do in order to implement the system. 


\section{Nomenclature}

$\begin{array}{ll}\text { GC } & \text { Gregorian Calendar } \\ \text { IFC } & \text { International Fixed Calendar } \\ \text { JC } & \text { Julian Calendar } \\ \text { PC } & \text { Perennial Calendar }\end{array}$

Funding: This research received no external funding.

Conflicts of Interest: The author declares no conflict of interest.

\section{References}

[1] M. Grant, "Roman religion," in Encyclopædia Britannica, ed. England: Encyclopædia Britannica, inc., 2016.

[2] J. Rüpke, The Roman calendar from Numa to Constantine: time, history, and the fasti. John Wiley \& Sons, 2011.

[3] A. K. Michels, Calendar of the Roman Republic. Princeton University Press, 2015.

[4] V. Emelianov, "Cultic Calendar and Psychology of Time: Elements of Common Semantics in Explanatory and Astrological Texts of Ancient Mesopotamia," Comparative Mythology, vol. 5, pp. 13-32, 2019.

[5] G. A. Barton, "Recent researches in the Sumerian calendar," Journal of the American Oriental Society, pp. 1-9, 1913.

[6] L. Brack-Bernsen, "The Observational Foundations of Babylonian Astronomy," in Hellenistic Astronomy: Brill, 2020, pp. 171-189.

[7] M. Boyce, "Further on the calendar of Zoroastrian feasts," Iran, vol. 43, no. 1, pp. 1-38, 2005.

[8] A. Dieckhoff, "Hebrew, the language of national daily life," in Language, nation and state: Identity politics in a multilingual age: Springer, 2004, pp. 187-199.

[9] M. Blomberg and G. Henriksson, "Literary and archaeoastronomical evidence for the origins of the Hellenic calendar in the Aegean Bronze Age," BAR INTERNATIONAL SERIES, vol. 1154, pp. 53-70, 2003.

[10] M. Dimitrijevic, E. T. Theodossiou, and P. Mantarakis, "Milutin Milankovic and the reform of the Julian Calendar in 1923," Journal of Astronomical History and Heritage, vol. 11, pp. 50-54, 2008.

[11] E. L. Cohen, "Adoption and reform of the Gregorian calendar," Math Horizons, vol. 7, no. 3, pp. 5-11, 2000.

[12] S. Joshi and U. Muley, "GREGORIAN CALENDAR," Bulletin of the Marathwada Mathematical Society, vol. 12, no. 1, pp. 65-75, 2011.

[13] H. H. Green, "Zenith Sun as the Means for Achieving Concordance Between the tonalpohualli and the Tropical Year Without Intercalation of Leap Days."

[14] M. B. Cotsworth, The Rational Almanac: Tracing the Evolution of Modern Almanacs from Ancient Ideas of Time, and Suggesting Improvements, with Years, Half-years and Quarters Equated; 13 Months to the Year; Holidays and Festivals, Also Week Days Fixed on Permanent Dates to Gain Much More Public Convenience; 180 Illustrations Explaining the Mystery of the Pyramids, Sphinx, Obelisks, Druidical Circles, Mounds, Vertical Stones, Etc., Erected to Record Yearly Almanac Times. Author, 1905.

[15] M. B. Cotsworth, "Proceedings and Transactions of the Royal Society of Canada, Third Series," 1908, vol. 2: Royal Society of Canada, 1908, pp. 211-241. [Online]. Available: https://ia802608.us.archive.org/3/items/proceedingstrans32roya/ proceedingstrans32roya.pdf.

[16] N. Dershowitz and E. M. Reingold, "Calendrical calculations," Software: Practice and Experience, vol. 20, no. 9, pp. 899-928, 1990.

[17] "One million calendars 'wrong due to bank holiday change'." BBC. https://www.bbc.com/news/uk-england-wiltshire$\underline{48661884}$ (accessed June 6, , 2020).

(C) 2020 by the authors. Submitted for possible open access publication under the terms and conditions of the Creative Commons Attribution (CC BY) license (http://creativecommons.org/licenses/by/4.0/). 